\title{
Removal of Toxic Metal Ions from Water Using Chelating Terpolymer Resin as a Function of Different Concentration Time and $\mathrm{pH}$
}

\author{
Mangesh S. Dhore, ${ }^{1}$ Suraj S. Butoliya, ${ }^{2}$ and Anil B. Zade ${ }^{1}$ \\ ${ }^{1}$ Department of Chemistry, Laxminarayan Institute of Technology, Rashtrasant Tukdoji Maharaj Nagpur University, \\ Nagpur 440 010, India \\ ${ }^{2}$ Department of Chemistry, Shri Ramdeobaba College of Engineering \& Management, Nagpur 440 013, India
}

Correspondence should be addressed to Anil B. Zade; ab_zade18@yahoo.com

Received 22 November 2013; Accepted 28 January 2014; Published 22 May 2014

Academic Editors: C.-Y. Guo, B. Haidar, and M. Sanopoulou

Copyright (C) 2014 Mangesh S. Dhore et al. This is an open access article distributed under the Creative Commons Attribution License, which permits unrestricted use, distribution, and reproduction in any medium, provided the original work is properly cited.

Terpolymer resin 4-ASAUF was synthesized by the condensation of 4-aminosalicylic acid (4-ASA) and urea (U) with formaldehyde (F) in the presence of $2 \mathrm{~N}$ hydrochloric acid. The structure of the resin was characterized by various spectral techniques like infrared (FTIR) and nuclear magnetic resonance $\left({ }^{1} \mathrm{H}\right.$ and $\left.{ }^{13} \mathrm{C}-\mathrm{NMR}\right)$ spectroscopy. The empirical formula and empirical weight of the resin were determined by elemental analysis. The physiochemical properties of terpolymer resin were determined. The morphological feature of the 4-ASAUF terpolymer resin was studied by scanning electron microscopy (SEM). The chelating ion-exchange property of this copolymer was studied for eight metal ions, namely, $\mathrm{Fe}^{3+}, \mathrm{Cu}^{2+}, \mathrm{Ni}^{2+}, \mathrm{Co}^{2+}, \mathrm{Hg}^{2+}, \mathrm{Zn}^{2+}, \mathrm{Cd}^{2+}$, and $\mathrm{Pb}^{2+}$ ions by using batch equilibrium method. The chelating ion-exchange study was carried out over a wide $\mathrm{pH}$ range at different time intervals using different electrolyte of various ionic strengths.

\section{Introduction}

Ion-exchange process is efficient and eco-friendly extraction technique for the separation of metal ions and recovery of toxic heavy metal ions from the industrial wastes, tannery effluents and sewages, and so forth $[1,2]$. The aromatic compound with substituents like $-\mathrm{OH},-\mathrm{COOH}$, and $-\mathrm{NH}_{2}$ with urea and formaldehyde shows selective ion-exchange properties, thermal resistance properties, and coordinating properties [3-6]. The chemically modified silica gel N-(1-carboxy6 hydroxy) benzylidenepropylamine was used as an ionexchanger for the removal and preconcentration of hazardous metal ions such as $\mathrm{Cr}, \mathrm{Mn}, \mathrm{Cd}$, and $\mathrm{Pb}$ in natural water samples using batch equilibrium method and atomic absorption spectroscopy (AAS) technique [7]. The metal absorption of copolymer gel poly(HPMA-co-IA) and poly(HPMA-co-CA) increases with $\mathrm{pH}$ and study proved that poly(HPMA-co-IA) and poly(HPMA-co-CA) could be used as metal absorbents for $\mathrm{Cd}^{2+}$ and $\mathrm{Pb}^{2+}$ ions [8]. Rahangdale et al. and Tarase et al. investigated the chelation ion-exchange properties of resin prepared from 2,4-dihydroxyacetophenone-biuretformaldehyde terpolymers and 2,4-dihydroxybenzaldehyde, oxamide, and formaldehyde, respectively $[9,10]$. The chelation ion-exchange properties of copolymer resin derived from 8-hydroxyquinoline 5-sulfonic acid, oxamide, and formaldehyde indicated that the copolymer had greater selectivity for $\mathrm{Fe}^{2+}, \mathrm{Cu}^{2+}$, and $\mathrm{Ni}^{2+}$ ions than for $\mathrm{Co}^{2+}, \mathrm{Zn}^{2+}$, $\mathrm{Cd}^{2+}$, and $\mathrm{Pb}^{2+}$ ions [11]. The metal ion-binding properties of a copolymer resin derived from o-aminophenol, melamine, and formaldehyde have been reported for the metal ions $\mathrm{Fe}^{3+}, \mathrm{Zn}^{2+}, \mathrm{Cu}^{2+}, \mathrm{Pb}^{2+}, \mathrm{Cd}^{2+}$, and $\mathrm{Hg}^{2+}[12]$. Gurnule et al. [13] reported that a copolymer prepared from salicylic acid, melamine, and formaldehyde was more selective for $\mathrm{Fe}^{3+}$, $\mathrm{Cu}^{2+}$, and $\mathrm{Ni}^{2+}$ ions than for $\mathrm{Co}^{2+}, \mathrm{Zn}^{2+}, \mathrm{Cd}^{2+}$, and $\mathrm{Pb}^{2+}$ ions. Butoliya et al. [14] reported a chelation ion-exchange properties of 2,4-dihydroxybenzophenone-oxamide-formaldehyde 


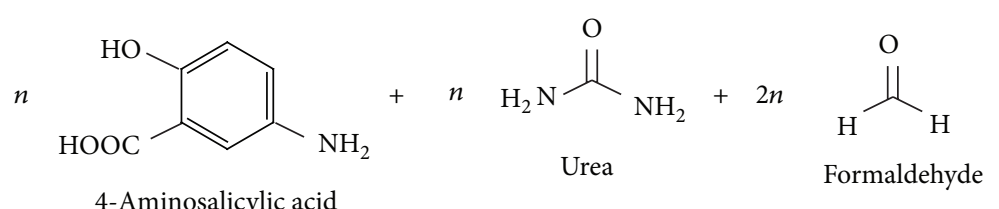<smiles>CC(C)(C)NC(=O)NCc1cc(O)c(C(=O)O)c(C(C)(C)C)c1N</smiles>

4-ASA-U-F-I terpolymer resin

Figure 1: Chemical reaction of 4-ASAUF terpolymer.

terpolymer resins. Ahamed et al. [15] synthesized a terpolymer from anthranilic acid, salicylic acid, and formaldehyde and evaluated its ion-exchange properties toward toxic metal ions. Similarly, Azarudeen et al. synthesized terpolymers from 8-hydroxyquinoline, anthranilic acid, and formaldehyde and determined their chelating capacity toward specific metal ions [16].

The present paper explored the newly synthesized terpolymer resin 4-aminosalicylic acid-urea-formaldehyde (4ASAUF) in the light of its physiochemical, spectral, and chelating ion-exchange study.

\section{Experimental}

2.1. Starting Materials. 4-Aminosalicylic acid is of analytical grade purity which is purchased from Acros Chemicals, Belgium. Urea, formaldehyde (37\%), metal nitrates, indicators, and disodium salt of ethylenediaminetetraacetic acid (EDTA) were purchased from S. D. Fine Chemicals, India. All the used solvents like N, N-dimethylformamide, dimethyl sulfoxide, tetrahydrofuran, acetone, and diethyl ether were procured from Merck, India. Double distilled water was used for all the experiments.

2.2. Synthesis. 4-ASAUF terpolymer was prepared by condensing 4-aminosalicylic acid (1.53 g, $0.1 \mathrm{~mol})$ and urea $(0.6 \mathrm{~g}$, $0.1 \mathrm{~mol})$ with formaldehyde $(7.5 \mathrm{~mL}, 0.2 \mathrm{~mol})$ in presence of $2 \mathrm{~N} \mathrm{HCl}$ as a catalyst in the molar proportion of $1: 1: 2$ at $120^{\circ} \mathrm{C}$ in an oil bath for $5 \mathrm{~h}$. The dark reddish brown resinous solid product was immediately removed, filtered, repeatedly washed with cold-distilled water, dried in air, and powdered with the help of mortar and pestle. The product obtained was extracted with diethyl ether to remove excess of 4aminosalicylic acid-formaldehyde copolymer which might be present along with 4-ASAUF terpolymer. Dried resin sample was dissolved in $8 \% \mathrm{NaOH}$, regenerated using 1:1 $\mathrm{HCl} /$ water $(v / v)$ with constant stirring, and filtered. This process was repeated twice. Resulting terpolymer sample was washed with boiling water and dried in a vacuum at room temperature. Purified terpolymer resin was finely ground to pass through 300-mesh size sieve and kept in a vacuum over silica gel [17]. The purity of newly synthesized and purified terpolymer resin sample has been tested and confirmed by thin layer chromatography technique. Dimethyl sulfoxide (DMSO) was used as a solvent for developing chromatogram and was allowed to run for about 20 minutes, when the chromatogram was exposed to iodine chamber; then we get single colour spot for resin sample. This indicates that the synthesized and purified polymer resin sample has no impurities and is used for further studies only after the confirmation of $100 \%$ purity of the sample. The chemical reaction of above synthesis is given in Figure 1.

2.3. Physiochemical Studies. Terpolymer was subject to elemental analysis for carbon, hydrogen, and nitrogen on Perkin Elmer 2400 Elemental Analyzer. Physiochemical studies such as moisture content, percentage solids, void volume fraction, true density, and sodium exchange capacity were evaluated in accordance with reported procedures [18].

2.4. Moisture Content. The purified $1 \mathrm{~g}$ of terpolymer was taken in a previously weight Petri dish. The Petri dish with terpolymer sample was then dried in a vacuum oven at $105^{\circ} \mathrm{C}$ 
for $8 \mathrm{~h}$ and reweighed after cooling in a desiccator. From the weight of the Petri dish, moisture content (\%) was calculated:

Moisture content

$=(($ Weight of the petri dish with terpolymer sample after drying)

- (Weight of the petri dish))

$\times(($ Weight of the petri dish with terpolymer sample before drying)

- (Weight of the petri dish) $)^{-1} \times 100$.

True density, apparent density, and void volume fraction were also calculated by use of the expressions:

$$
\text { True density }\left(d_{\text {pol }}\right)=\frac{W_{p}-W}{\left(W_{w}-W_{p w}\right)+\left(W_{p}-W\right)},
$$

where $W$ is weight of the specific gravity bottle, $W_{p}$ is weight of the specific gravity bottle containing terpolymer, $W_{w}$ is weight of the specific gravity bottle containing water, and $W_{p w}$ is weight of the specific gravity bottle containing both terpolymer and water.

$$
\begin{gathered}
\text { Apparent density }\left(d_{\text {col }}\right)=\frac{\text { Weight of terpolymer }}{\text { Volume of terpolymer }} \\
\text { Void volume fraction }=1-\frac{d_{\text {col }}}{d_{\text {pol }}}
\end{gathered}
$$

2.5. Total Exchange Capacity. The total exchange capacity of the terpolymer is the total number of exchanging sites available per unit volume of swollen terpolymer. Dry terpolymer (1.0 g, accurately weighed, $\mathrm{H}^{+}$form) of uniform particle size (30-60 mesh) was placed in a $250 \mathrm{~mL}$ Erlenmeyer flask. To this, $200 \mathrm{~mL}$ standard solution of $0.1 \mathrm{M} \mathrm{NaOH}$ in $1 \mathrm{M}$ $\mathrm{NaCl}$ was added. The mixture was equilibrated for $24 \mathrm{~h}$ with intermittent shaking. After $24 \mathrm{~h}, 50 \mathrm{~mL}$ of the mixture was withdrawn and titrated against standard $0.1 \mathrm{M} \mathrm{HCl}$ solution. The total cation- exchange capacity (CEC) was calculated from

$$
\begin{aligned}
\mathrm{CEC}= & \frac{(200 \times \text { molarity of } \mathrm{NaOH})}{\text { weight of sample } \times[\text { solid }(\%) / 100]} \\
& -\frac{(4 \times \text { volume of } \mathrm{HCl} \times \text { molarity of } \mathrm{HCl})}{\text { weight of sample } \times[\text { solid }(\%) / 100]},
\end{aligned}
$$

where CEC is the cation-exchange capacity of the terpolymer.

2.6. Spectral Studies. Infrared spectra were recorded in Frontier transform infrared spectrophotometer in the range of 4000-500 $\mathrm{cm}^{-1} .{ }^{1} \mathrm{H}$ and ${ }^{13} \mathrm{C}-\mathrm{NMR}$ studies were performed in dimethyl sulfoxide (DMSO- $\mathrm{d}_{6}$ ) solvent on Bruker AdvanceII $400 \mathrm{MHz}$ and ${ }^{13} \mathrm{C}-\mathrm{NMR}$ spectrum was also recorded using Bruker $100 \mathrm{MHz}$.
2.7. Ion-Exchange Property. The ion-exchange property of the 4-ASAUF terpolymer resin was studied by using batch equilibrium method for various metal ions, namely, $\mathrm{Fe}^{3+}$, $\mathrm{Cu}^{2+}, \mathrm{Ni}^{2+}, \mathrm{Co}^{2+}, \mathrm{Hg}^{2+}, \mathrm{Zn}^{2+}, \mathrm{Cd}^{2+}$, and $\mathrm{Pb}^{2+}$ under three different experimental conditions $[4,19]$.

(i) Determination of Metal Uptake in the Presence of Four Different Electrolytes and Their Different Concentrations. Terpolymer sample $(25 \mathrm{mg})$ was placed in cleaned glass bottles and each of the electrolytes $(25 \mathrm{~mL}), \mathrm{NaCl}, \mathrm{NaNO}_{3}, \mathrm{NaClO}_{4}$, and $\mathrm{Na}_{2} \mathrm{SO}_{4}$, at different concentrations, namely, 0.01, 0.05, $0.1,0.5$, and $1 \mathrm{M}$, was added into the bottles. The suspensions were adjusted to $\mathrm{pH} 2.5$ for $\mathrm{Fe}^{3+}, \mathrm{pH} 4.5$ for $\mathrm{Cu}^{2+}$ and $\mathrm{Hg}^{2+}$, pH 5.0 for $\mathrm{Co}^{2+}, \mathrm{Cd}^{2+}, \mathrm{Ni}^{2+}$, and $\mathrm{Zn}^{2+}$, and $\mathrm{pH} 6$ for $\mathrm{Pb}^{2+}$ by adding either $0.1 \mathrm{M} \mathrm{HCl}$ or $0.1 \mathrm{M} \mathrm{NaOH}$. The suspensions were mechanically stirred for $24 \mathrm{~h}$ at room temperature. After $24 \mathrm{~h}, 0.1 \mathrm{M}$ of the chosen metal ion solution $(2 \mathrm{~mL})$ was added to each bottle and these were again vigorously stirred at room temperature for $24 \mathrm{~h}$. The terpolymer was then isolated by filtration and washed with distilled water. The filtrate and the washings were collected and the amount of metal ion was estimated by titrating against standard disodium EDTA solution using an appropriate indicator. A blank experiment was also performed by following the same procedure without the terpolymer sample. The amount of metal ions taken up by the terpolymer in the presence of a given electrolyte can be calculated from the difference between the actual titration reading and that of the blank reading.

(ii) Estimation of Rate of Metal Ion Uptake as a Function of Time. In order to estimate the time required to reach the state of equilibrium under the given experimental conditions, a series of experiments of the type described above were carried out, in which the metal ion taken up by the chelating resins was determined from time to time at room temperature (in the presence of $25 \mathrm{~mL}$ of $1 \mathrm{M} \mathrm{NaNO}_{3}$ solution). It was assumed that, under the given conditions, the state of equilibrium was established within $24 \mathrm{~h}$. The rate of metal uptake is expressed as percentage of the amount of metal ions taken up after a certain time related to that at the state of equilibrium and it can be defined by the following relationship. The percentage amount of metal ions taken up at different time is defined as

Percentage of metal ion taken up at equilibrium

$$
\begin{aligned}
= & (\text { Amount of metal ion adsorbed }(\text { after } 1 \mathrm{~h}) \\
& \times(\text { Amount of metal ion adsorbed at equilibrium }
\end{aligned}
$$

$$
\left.(\operatorname{after} 24 \mathrm{~h}))^{-1}\right) \times 100 \text {. }
$$

Using this expression, the amount of metal adsorbed by terpolymer after specific time intervals was calculated and expressed in terms of percentage metal ion adsorbed. This experiment was performed using $0.1 \mathrm{M}$ metal nitrate 


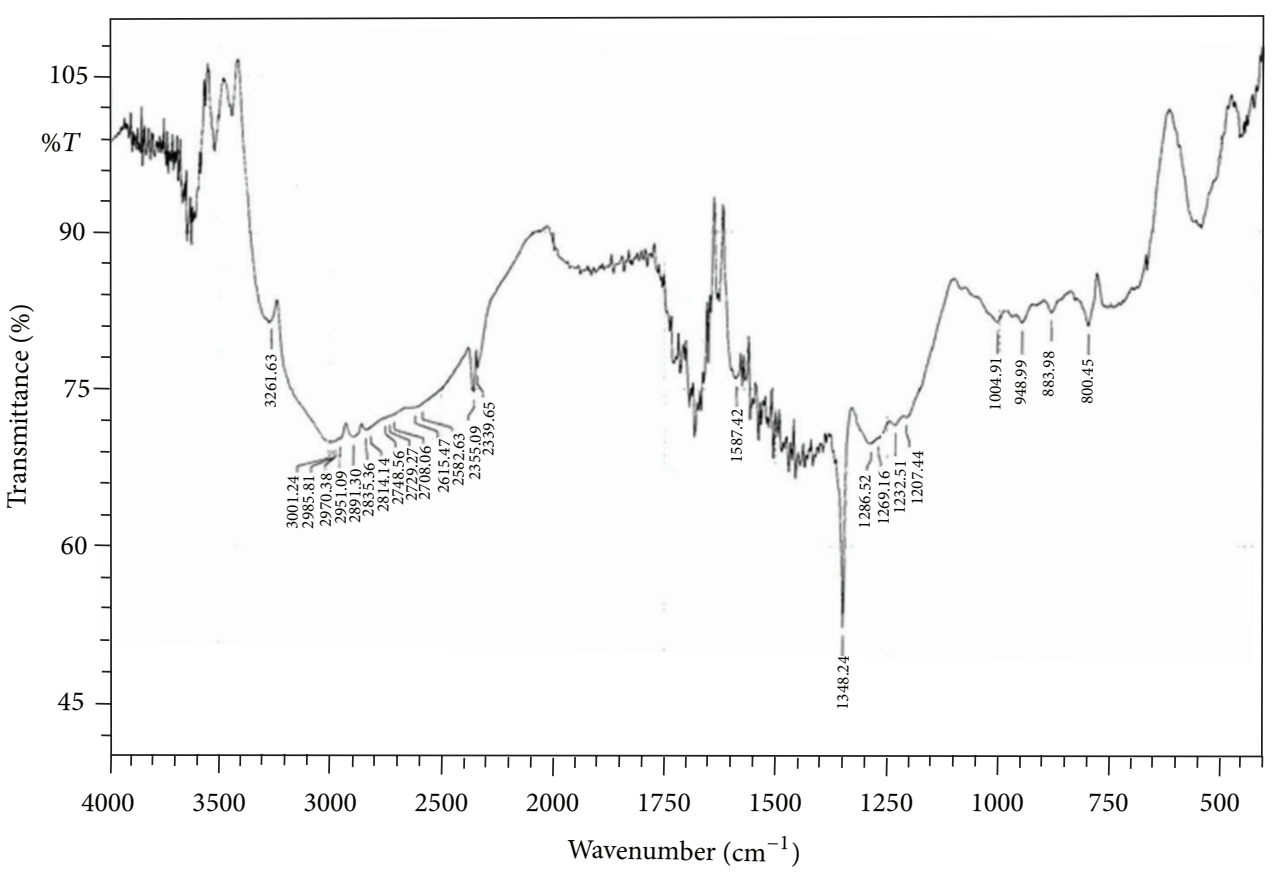

FIGURE 2: FT-IR spectra of4-ASAUF terpolymer.

solution of $\mathrm{Fe}^{3+}, \mathrm{Cu}^{2+}, \mathrm{Ni}^{2+}, \mathrm{Co}^{2+}, \mathrm{Hg}^{2+}, \mathrm{Zn}^{2+}, \mathrm{Cd}^{2+}$, and $\mathrm{Pb}^{2+}$.

(iii) Evaluation of the Distribution of Metal Ions at Different $p H$. The distribution of each one of the eight metal ions, that is, $\mathrm{Fe}^{3+}, \mathrm{Cu}^{2+}, \mathrm{Ni}^{2+}, \mathrm{Co}^{2+}, \mathrm{Hg}^{2+}, \mathrm{Zn}^{2+}, \mathrm{Cd}^{2+}$, and $\mathrm{Pb}^{2+}$ between the polymer phase and the aqueous phase, was determined at room temperature and in the presence of $1 \mathrm{M} \mathrm{NaNO}_{3}$ solution. The experiments were carried out as described above at different $\mathrm{pH}$ values. The distribution ratio, $D$, is defined by the following relationship [20]:

$$
\begin{aligned}
D= & \frac{\text { Amount of metal ion on resin }}{\text { Amount of metal ion in solution }} \\
& \times \frac{\text { Volume of solution }(\mathrm{mL})}{\text { Weight of resin }(\mathrm{g})},
\end{aligned}
$$

Metal ion adsorbed (uptake) by the resin

$$
=\left(\frac{Z X}{Y}\right) \frac{2}{0.025}
$$

where " $Z$ " is the difference between actual experiment reading and blank reading, " $X$ " gram is the amount of metal ion in $2 \mathrm{~mL} 0.1 \mathrm{M}$ metal nitrate solution before uptake, and " $Y$ " gram of metal ion in $2 \mathrm{~mL}$ of metal nitrate solution after uptake.

\section{Results and Discussion}

3.1. Physicochemical Properties. The moisture content of the 4-ASAUF terpolymer resin is $3.4 \%$. The moisture content

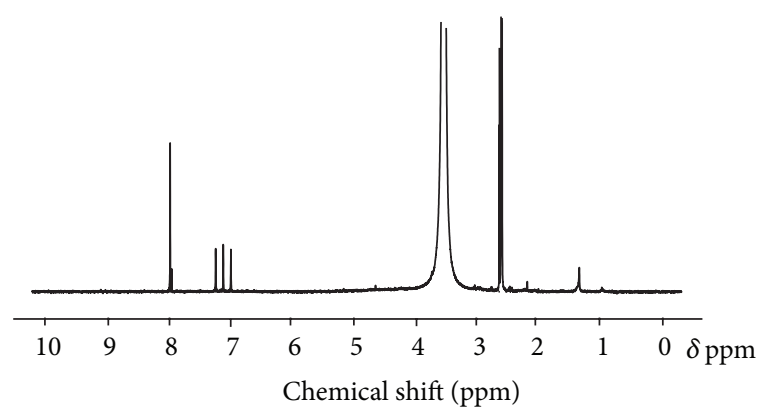

Figure $3:{ }^{1} \mathrm{H}-\mathrm{NMR}$ spectrum of 4-ASAUF terpolymer.

of commercial resins (cationic form) is $43-53 \%$ for IRC50/75 (weak acid, active group, and $\mathrm{COO}^{-}$) and 42-50 for IRC-84 (weak acid, active group, and $\mathrm{COO}^{-}$). Hence, the terpolymer had low moisture content. The value of true density of the resin is $1.113 \mathrm{~g} / \mathrm{cm}^{3}$. The true density of a commercial resin generally lies between 1.10 and $1.50 \mathrm{~g} / \mathrm{cm}^{3}$. Hence, the result found is in close agreement with the values for commercial resins. The void volume fraction of the terpolymer was 0.780 . The void volume fraction aids diffusion of exchangeable ions on the resin and hence increases the rate of exchange of ions. The sodium exchange capacity of 4-ASAUF terpolymer resin was $3.26 \mathrm{mmol} \mathrm{g}^{-1}$ dry resins. This may be because of the high value of void volume fraction and also because of the presence of carboxylic acid $(-\mathrm{COOH})$, amine $\left(-\mathrm{NH}_{2}\right)$, and hydroxyl $(-\mathrm{OH})$ groups in the resin. The results from determination of the physicochemical properties of 4-ASAUF terpolymer resin are given in Table 1. 
TABLE 1: Physiochemical properties and elemental analysis data of 4-ASAUF terpolymer.

\begin{tabular}{|c|c|c|c|c|c|c|c|}
\hline \multirow{2}{*}{ Terpolymer } & \multirow{2}{*}{$\begin{array}{l}\text { Monomer empirical } \\
\text { formula }\end{array}$} & \multirow{2}{*}{$\begin{array}{l}\text { Empirical formula } \\
\text { weight }\end{array}$} & \multirow{2}{*}{ Properties } & \multirow{2}{*}{ Value } & \multicolumn{3}{|c|}{ Elemental analysis (\%) } \\
\hline & & & & & $\mathrm{C}$ & $\mathrm{H}$ & $\mathrm{N}$ \\
\hline \multirow{5}{*}{ 4-ASAUF } & \multirow{5}{*}{$\mathrm{C}_{10} \mathrm{H}_{11} \mathrm{~N}_{3} \mathrm{O}_{4}$} & \multirow{5}{*}{237.21} & Moisture (\%) & $3.4 \pm 0.25$ & \multirow{5}{*}{50.42} & \multirow{5}{*}{4.48} & \multirow{5}{*}{17.13} \\
\hline & & & Solids (\%) & $96.6 \pm 0.25$ & & & \\
\hline & & & True density (dry resin) $\mathrm{g} / \mathrm{cm}^{3}$ & $1.113 \pm 0.05$ & & & \\
\hline & & & Void volume fraction & $0.780 \pm 0.015$ & & & \\
\hline & & & $\begin{array}{l}\mathrm{Na}^{+} \text {exchange capacity } \\
\left(\mathrm{mmolg}{ }^{-1} \text { dry resin }\right)\end{array}$ & $3.26 \pm 0.10$ & & & \\
\hline
\end{tabular}

TABLE 2: IR frequencies of 4-ASAUF terpolymer.

\begin{tabular}{lcr}
\hline $\begin{array}{l}\text { Observed band } \\
\text { frequencies }\left(\mathrm{cm}^{-1}\right)\end{array}$ & Vibrational mode & Expected band frequencies $\left(\mathrm{cm}^{-1}\right)$ \\
\hline $3351.0 \mathrm{~b}, \mathrm{st}$ & $-\mathrm{OH}$ (phenolic) & $3200-3400$ \\
$3001.2 \mathrm{st}, \mathrm{w}$ & $-\mathrm{NH}-($ amino $)$ & $>3000$ \\
$2891.3 \mathrm{~m}, \mathrm{st}$ & $-\mathrm{CH}_{2}-$ stretching methylene bridge & $2800-2950$ \\
$1450.6-1540.4 \mathrm{~m}$ & $>\mathrm{C}=\mathrm{C}<$ in aromatics & $1400-1600$ \\
$1269.1 \mathrm{st}$ & Carboxylic acid -COOH & $1250-1300$ \\
$1587.4 \mathrm{st}$ & Ar- $\mathrm{NH}_{2}$ (amine) & $1560-1640$ \\
$1207.44 \mathrm{sh}, \mathrm{m}$ & $\mathrm{C}-\mathrm{O}$ str. in phenol & 1200 \\
$800.4 \mathrm{sh}, \mathrm{w}$ & Pentasubstituted benzene ring & $800-950$ \\
$848.8 \mathrm{sh}, \mathrm{w}$ & &
\end{tabular}

Sh: sharp; b: broad; st: strong; m: medium; and w: weak.

3.2. Elemental Analysis. The yield of resin was found to be $85 \%$. Composition of terpolymer was obtained on the basis of elemental analysis data and was found to be in good correlation to that of calculated values as given in Table 1.

\section{Spectral Studies of 4-ASAUF Terpolymer}

4.1. FT-IR Spectra. The FTIR-spectrum of 4-ASAUF terpolymer is represented in Figure 2 and the data is reported in Table 2. Broad band appeared at $3281.63 \mathrm{~cm}^{-1}$, which may be assigned to the stretching vibration of the phenolic $-\mathrm{OH}$ groups exhibiting intermolecular hydrogen bonding [21, 22]. The presence of a weak peak at $3001.2 \mathrm{~cm}^{-1}$ describes the -NH- in urea moiety which might be present in terpolymer chain [22]. The broad band appearing in the spectrum at $3410.4 \mathrm{~cm}^{-1}$ is assigned to the hydroxyl group of $-\mathrm{COOH}$ present in the aromatic ring and involves intramolecular hydrogen bonding with the $-\mathrm{NH}$ of $\mathrm{Ar}-\mathrm{NH}_{2}$ [23]. This band seems to be merged with the band arising from $-\mathrm{NH}$ stretching vibrations of the $\mathrm{Ar}-\mathrm{NH}_{2}$ group, and this is further confirmed by the $-\mathrm{NH}$ bending vibrations appearing at $1587.4 \mathrm{~cm}^{-1}$ [24]. A sharp and weak peak obtained at $2891.3 \mathrm{~cm}^{-1}$ indicates the presence of stretching vibrations of methylene group $\left(-\mathrm{CH}_{2}-\right)$ in the copolymer chain $[22,25]$. A medium band, displayed between 1450.6 and $1540.4 \mathrm{~cm}^{-1}$, may be due to stretching vibration of $>\mathrm{C}=\mathrm{C}<$ in aromatics. Broad and strong bands were displayed at $1269.16 \mathrm{~cm}^{-1}$ for confirming the presence of $>\mathrm{C}=\mathrm{O}$ stretching vibration of carboxylic acid group in the terpolymer chain [22].
$>\mathrm{C}=\mathrm{O}$ stretch in phenol is represented at $1207.4 \mathrm{~cm}^{-1}$. The presence of pentasubstitution of aromatic ring [22] is recognized from the weak bands appearing in the range $800.46-848.88 \mathrm{~cm}^{-1}$.

4.2. ${ }^{1} H$-NMR Spectra. ${ }^{1} \mathrm{H}-\mathrm{NMR}$ spectral data is given in Table 3 and spectrum is presented in Figure 3. Spectra revealed different patterns of peaks, since each of them possesses a set of protons having different proton environment. A significant downfield in chemical shift of proton of phenolic -OH group, observed at $\delta=4.7 \mathrm{ppm}$, is due to intermediate proton exchange reaction of phenolic-OH group [26-28]. A weak singlet is observed at $\delta=7.5 \& \delta=8.1 \mathrm{ppm}$ and is due to ortho- and metaprotons of phenol, respectively. In urea moiety, the singlet observed in the regions $\delta=7.1$ and $\delta=$ 7.2 is due to two $\mathrm{CH}_{2}-\mathrm{NH}-\mathrm{C}=\mathrm{O}$ and singlet observed in the region $\delta=3.9 \mathrm{ppm}$ is due to methylene proton of $\mathrm{Ar}-\mathrm{CH}_{2}-$ $\mathrm{NH}$. A broad singlet observed at $\delta=3.8 \mathrm{ppm}$ may be assigned to proton of $\mathrm{Ar}-\mathrm{NH}_{2}$. Singlet observed at $\delta=2.70 \mathrm{ppm}$ and $\delta=8.2 \mathrm{ppm}$ is due to the proton of $\mathrm{Ar}-\mathrm{CH}_{2}$ and $\mathrm{Ar}-\mathrm{COOH}$, respectively, $[22,26]$.

4.3. ${ }^{13} \mathrm{C}-\mathrm{NMR}$ Spectra. The ${ }^{13} \mathrm{C}-\mathrm{NMR}$ spectrum of 4 -ASAUF terpolymer is shown in Figure 4 and observed chemical shift is assigned on the basis of the literature $[21,26]$. The $C_{1}$ to $\mathrm{C}_{6}$ of the aromatic ring shows the peaks at 113.4, 137.8, $140.1,116.2,114.6$, and $157.2 \mathrm{ppm}$, respectively, and the peaks that appeared at $77.3 \mathrm{ppm}$ are assigned to the methylene carbon of $\mathrm{Ar}-\mathrm{CH}_{2}-\mathrm{NH}$ linkage [19]. The peaks that appeared 
TABLE 3: ${ }^{1} \mathrm{H}$-NMR spectral data of 4-ASAUF terpolymer.

\begin{tabular}{lcc}
\hline Nature of protons assigned & Expected chemical shift $(\delta)$ ppm & Observed chemical shift $(\delta)$ ppm of copolymer \\
\hline $1 \mathrm{H}$, phenolic $-\mathrm{OH}(\mathrm{S})$ & $3.5-9$ & 4.7 \\
$1 \mathrm{H}, \mathrm{Ar}-\mathrm{H}(\mathrm{S})$ & $6.5-9$ & 7.5 and 8.1 \\
$2 \mathrm{H}, \mathrm{Ar}-\mathrm{NH}_{2}(\mathrm{~S})$ & $3.2-6$ & 3.8 \\
$1 \mathrm{H}, \mathrm{Ar}-\mathrm{COOH}(\mathrm{S})$ & $10-13$ & 8.2 \\
$1 \mathrm{H}, \mathrm{CH}_{2}-\mathrm{NH}-\mathrm{C}=\mathrm{O}(\mathrm{S})$ & $5-8$ & 7.1 and 7.2 \\
$2 \mathrm{H}, \mathrm{Ar}-\mathrm{CH}_{2}-\mathrm{NH}$ in Urea moiety (S) & $2.5-3.5$ & 3.9 \\
$2 \mathrm{H}, \mathrm{NH}-\mathrm{CH}_{2}(\mathrm{~S})$ & $1.5-3.5$ & 2.70
\end{tabular}

S: stand for singlet.

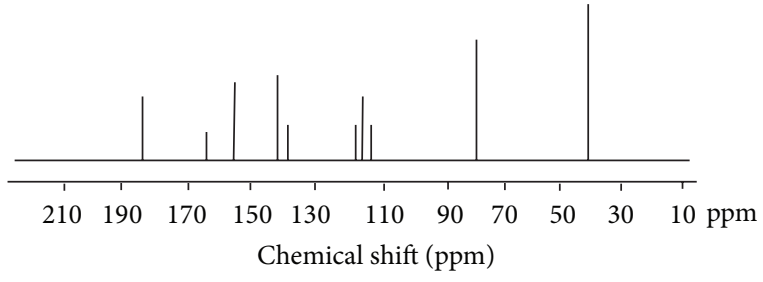

Figure $4:{ }^{13} \mathrm{C}$ NMR spectrum of 4-ASAUF terpolymer.

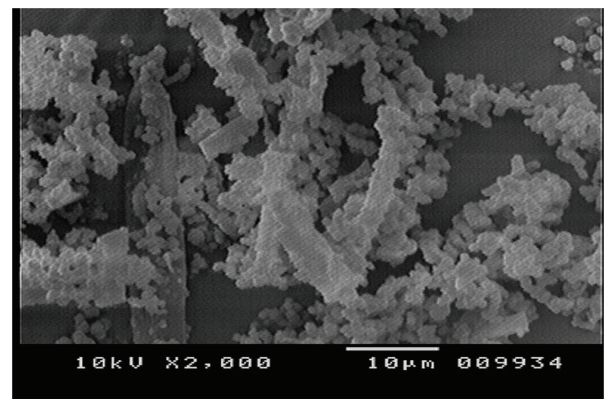

FIGURE 5: SEM image of 4-ASAUF terpolymer.

at $176.4 \mathrm{ppm}$ are due to the $-\mathrm{C}=\mathrm{O}$ of the $\mathrm{Ar}-\mathrm{COOH}$ and peaks at $163.1 \& 38.4 \mathrm{ppm}$ are assigned to $\mathrm{C}=\mathrm{O}$ of urea moiety and carbon of $\mathrm{NH}-\mathrm{CH}_{2}$ [29]. The results are obtained from spectral analysis; the structure of the terpolymer resin was clearly elucidated.

4.4. SEM Analysis. The typical microphotograph at 2,000 magnification from SEM of 4-ASAUF is shown in Figure 5. The SEM image shows the surface future of the sample. The image of the 4-ASAUF is clearly indicative of a loosely close packed structure with high porosity or voids. The voids presented in the terpolymer ligands may be responsible for the swelling behavior and reactivity of active sites buried in the polymer matrix and also responsible for exchange of metal ion. The image also showed a transition state between the amorphous and crystalline states. However, more predominantly, the terpolymer is amorphous, because of the polycondensation reaction [29].
4.5. Ion-Exchange Properties. The ion-exchange properties of the given terpolymer resin were studied by batch equilibrium technique developed by DeGeiso et al. [30] and Gregor et al. [31]. This technique was used to study ion-exchange properties of 4-ASAUF terpolymer resin and results are presented in Tables 4-6. Eight metal ions $\mathrm{Fe}^{3+}, \mathrm{Cu}^{2+}, \mathrm{Ni}^{2+}$, $\mathrm{Co}^{2+}, \mathrm{Hg}^{2+}, \mathrm{Zn}^{2+}, \mathrm{Cd}^{2+}$, and $\mathrm{Pb}^{2+}$ in the form of aqueous metal nitrate solution were used. The ion-exchange study was carried out using three experimental variables such as (a) electrolyte and its ionic strength, (b) uptake time, and (c) $\mathrm{pH}$ of the aqueous medium. Among these three variables, two were kept constant and only one was varied at a time to evaluate its effect on metal uptake of the polymer similar to the earlier coworkers $[4,19]$.

(i) Determination of Metal Uptake in the Presence of Four Different Electrolytes and Their Different Concentrations. We examined the influence of nitrate $\left(\mathrm{NO}_{3}{ }^{-}\right)$, chloride $\left(\mathrm{Cl}^{-}\right)$, chlorate $\left(\mathrm{ClO}_{4}{ }^{-}\right)$, and sulfate $\left(\mathrm{SO}_{4}{ }^{2-}\right)$ at various concentrations on the equilibrium of metal-resin interaction. The aim of this study is to investigate the effect of the various electrolytes with different concentrations on the amount of the metal ions taken up by terpolymer sample which might be used in the purification of waste solution. The results are presented in Table 4 and chelate formation by the 4-ASAUF terpolymer is shown in Figure 6. This reveals the fact that the amount of metal ions taken up by a given amount of terpolymer depends on the nature and concentration of the electrolyte present in the solution. Generally, as concentration of the electrolyte increases, the ionization decreases, and number of ligands (negative ions of electrolyte) decreases in the solution which forms the complex with less number of metal ions and therefore more numbers of ions may be available for adsorption on terpolymer. Hence, on increasing concentration, uptake of metal ions may be increased, which is the normal trend. But the trend is different in different electrolytes and their different concentrations due to the formation of more or less stable complexes of electrolyte ligand or terpolymer with metal ions (see Figure 7).

If electrolyte ligand-metal ion complex is weaker than polymer-metal ion chelates, the more numbers of metal ions can form complex with polymer; hence, uptake of metal ion is more. But if this complex is stronger than polymer-metal ion 
TABLE 4: Evaluation of the effect of different electrolytes and their concentrations on the uptake of 4-ASAUF terpolymer resins.

\begin{tabular}{|c|c|c|c|c|c|c|}
\hline \multirow{2}{*}{ Metal ion } & \multirow{2}{*}{ Electrolyte (mol/L) } & \multirow{2}{*}{$\mathrm{pH}$} & \multicolumn{4}{|c|}{ Weight of metal uptake $\left(\mathrm{mmol} \mathrm{g}^{-1}\right)$ in the presence of } \\
\hline & & & $\mathrm{NaNO}_{2}$ & $\mathrm{Na}_{2} \mathrm{SO}_{4}$ & $\mathrm{NaCl}$ & $\mathrm{NaClO}_{4}$ \\
\hline \multirow{5}{*}{$\mathrm{Fe}^{3+}$} & 0.01 & \multirow{5}{*}{2.5} & 1.14 & 2.11 & 1.22 & 1.0 \\
\hline & 0.05 & & 1.64 & 1.53 & 1.84 & 1.22 \\
\hline & 0.10 & & 2.21 & 1.33 & 2.33 & 1.56 \\
\hline & 0.50 & & 2.72 & 1.11 & 2.86 & 1.78 \\
\hline & 1.00 & & 3.21 & 0.42 & 3.48 & 2.18 \\
\hline \multirow{5}{*}{$\mathrm{Cu}^{2+}$} & 0.01 & \multirow{5}{*}{4.5} & 1.11 & 2.77 & 1.21 & 0.74 \\
\hline & 0.05 & & 1.42 & 2.22 & 1.71 & 1.12 \\
\hline & 0.10 & & 1.73 & 1.76 & 2.26 & 1.49 \\
\hline & 0.50 & & 2.1 & 1.21 & 2.68 & 1.74 \\
\hline & 1.00 & & 2.74 & 0.83 & 3.1 & 2.10 \\
\hline \multirow{5}{*}{$\mathrm{Hg}^{2+}$} & 0.01 & \multirow{5}{*}{4.5} & 0.82 & 1.71 & 1.1 & 0.84 \\
\hline & 0.05 & & 1.24 & 1.21 & 1.65 & 1.12 \\
\hline & 0.10 & & 1.54 & 1.0 & 2.32 & 1.52 \\
\hline & 0.50 & & 2.00 & 0.69 & 2.86 & 1.84 \\
\hline & 1.00 & & 2.35 & 0.25 & 3.24 & 2.18 \\
\hline \multirow{5}{*}{$\mathrm{Cd}^{2+}$} & 0.01 & \multirow{5}{*}{5.0} & 0.39 & 1.82 & 1.0 & 0.84 \\
\hline & 0.05 & & 0.76 & 1.41 & 1.31 & 1.14 \\
\hline & 0.10 & & 1.14 & 1.00 & 1.55 & 1.39 \\
\hline & 0.50 & & 1.45 & 0.76 & 1.88 & 1.59 \\
\hline & 1.00 & & 1.73 & 0.43 & 2.10 & 1.74 \\
\hline \multirow{5}{*}{$\mathrm{Co}^{2+}$} & 0.01 & \multirow{5}{*}{5.0} & 1.17 & 1.91 & 0.76 & 0.72 \\
\hline & 0.05 & & 1.42 & 1.28 & 1.0 & 1.1 \\
\hline & 0.10 & & 1.77 & 0.94 & 1.22 & 1.42 \\
\hline & 0.50 & & 2.10 & 0.74 & 1.56 & 1.84 \\
\hline & 1.00 & & 2.34 & 0.56 & 1.84 & 2.1 \\
\hline \multirow{5}{*}{$\mathrm{Zn}^{2+}$} & 0.01 & \multirow{5}{*}{5.0} & 0.34 & 1.54 & 0.92 & 0.74 \\
\hline & 0.05 & & 0.81 & 1.22 & 1.11 & 0.94 \\
\hline & 0.10 & & 1.26 & 1.1 & 1.54 & 1.41 \\
\hline & 0.50 & & 1.54 & 0.77 & 1.86 & 1.77 \\
\hline & 1.00 & & 2.20 & 0.52 & 2.30 & 1.94 \\
\hline \multirow{5}{*}{$\mathrm{Ni}^{2+}$} & 0.01 & \multirow{5}{*}{5.0} & 1.21 & 2.26 & 1.18 & 1.21 \\
\hline & 0.05 & & 1.43 & 2.42 & 1.46 & 1.46 \\
\hline & 0.10 & & 1.86 & 2.21 & 2.0 & 1.76 \\
\hline & 0.50 & & 2.26 & 1.59 & 2.35 & 2.23 \\
\hline & 1.00 & & 2.63 & 1.11 & 2.62 & 2.41 \\
\hline \multirow{5}{*}{$\mathrm{Pb}^{2+}$} & 0.01 & \multirow{5}{*}{6.0} & 0.42 & 1.43 & 0.85 & 0.50 \\
\hline & 0.05 & & 0.77 & 1.12 & 0.96 & 0.76 \\
\hline & 0.10 & & 1.17 & 0.84 & 1.22 & 1.1 \\
\hline & 0.50 & & 1.52 & 0.52 & 1.41 & 1.27 \\
\hline & 1.00 & & 1.78 & 0.36 & 1.59 & 1.53 \\
\hline
\end{tabular}

chelates, more numbers of metal ions form strong complex with electrolyte ligand which make metal uptake capacity lower by polymer.

In the presence of nitrate $\left(\mathrm{NO}_{3}{ }^{-}\right)$, chloride $\left(\mathrm{Cl}^{-}\right)$, and chlorate $\left(\mathrm{ClO}_{4}{ }^{-}\right)$, the uptake of $\mathrm{Fe}^{3+}, \mathrm{Cu}^{2+}, \mathrm{Ni}^{2+}, \mathrm{Co}^{2+}$, $\mathrm{Hg}^{2+}, \mathrm{Zn}^{2+}, \mathrm{Cd}^{2+}$, and $\mathrm{Pb}^{2+}$ ions increases with increasing concentration of the electrolyte, whereas in the presence of sulfate $\left(\mathrm{SO}_{4}{ }^{2-}\right)$ ions the amount of the above-mentioned ions taken up by the terpolymer decreases with increasing concentration of the electrolyte [19].

The ratio of physical core structure of the resin is significant in the uptake of different metal ions by the terpolymer. 


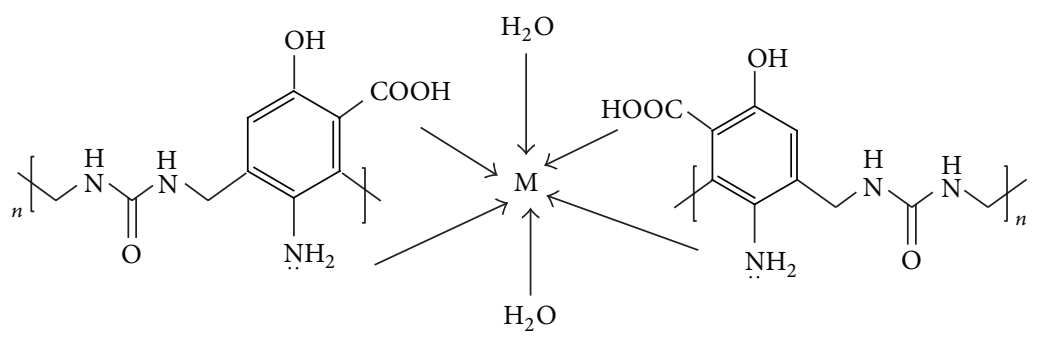

FIGURE 6: Chelate structure of the 4-ASAUF terpolymer resin.

Electrolyte solution + metal ion solution + polymer

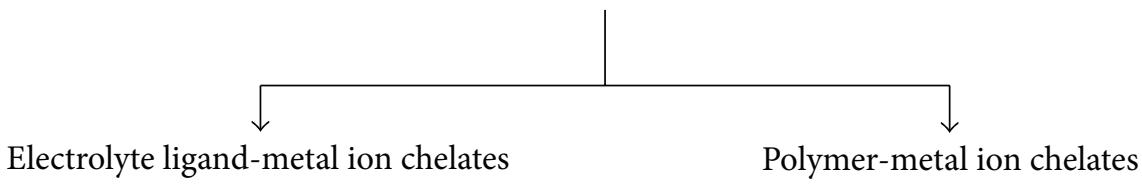

Figure 7

The rate of metal ion uptake for $\mathrm{NO}_{3}{ }^{-}, \mathrm{Cl}^{-}, \mathrm{ClO}_{4}{ }^{-}$, and $\mathrm{SO}_{4}{ }^{2-}$ electrolytes at various concentrations follows the order as $\mathrm{Fe}^{3+}>\mathrm{Cu}^{2+} \approx \mathrm{Ni}^{2+}>\mathrm{Co}^{2+} \approx \mathrm{Hg}^{2+} \approx \mathrm{Zn}^{2+}>\mathrm{Cd}^{2+} \approx \mathrm{Pb}^{2+}$.

The amount of metal ion uptake by the 4-ASAUF terpolymer resin is found to be higher when comparing to the other copolymer resins $[2,4,13,20]$. The uptake of metal ions by the terpolymer resin was calculated by use of the formula and expressed in $\mathrm{mmol} \mathrm{g}^{-1}$ :

Metal ion adsorbed (uptake) by resin

$$
=(X-Y) Z \mathrm{mmol} / \mathrm{g}^{-1},
$$

where " $Z$ " $\mathrm{mL}$ is the difference between actual experimental reading and blank reading. " $X$ " $\mathrm{mg}$ is metal ion in the $2 \mathrm{~mL}$ $0.1 \mathrm{M}$ metal nitrate solution before uptake. " $Y$ " $\mathrm{mg}$ is metal ion in the $2 \mathrm{~mL} 0.1 \mathrm{M}$ metal nitrate solution after uptake.

By using this equation the uptake of various metal ions by resin can be calculated and expressed in terms of millimole per gram of the terpolymer. Thus the metal intake of resin was analyzed by mass balance calculation.

(ii) Estimation of Rate of Metal Ion Uptake as a Function of Time. The rate of metal adsorption was determined to find out the shortest period of time for which equilibrium could be achieved while operating as close to equilibrium conditions as possible. As shaking time increases, the terpolymer gets more time for adsorption; hence uptake increases. The data of dependence of the rate of metal ion uptake on the nature of the metal ions is shown in Table 5. The rate refers to the change in the concentration of the metal ions in the aqueous solution which is in contact with the given terpolymer. The results show that the rate of metal uptake may depend upon the nature of the metal ions and their ionic size. Thus the rate of metal ion uptake follows the order:
Metal ion (Ionic size): $\mathrm{Fe}^{3+}(0: 55)>\mathrm{Cu}^{2+}(0: 57) \approx$ $\mathrm{Ni}^{2+}(0: 69)>\mathrm{Co}^{2+}(0: 90) \approx \mathrm{Hg}^{2+}(0: 90) \approx \mathrm{Zn}^{2+}(0: 90)$ $>\mathrm{Cd}^{2+}(1: 10) \approx \mathrm{Pb}^{2+}(1: 19)$.

The sequence of rate of metal ion uptake indicates that the rate is directly proportional to the size of the metal ion. For example, $\mathrm{Fe}^{3+}$ has more charges and small sizes; therefore equilibrium is attained within three hours, while other four transition ions $\mathrm{Cu}^{2+}, \mathrm{Ni}^{2+}, \mathrm{Co}^{2+}, \mathrm{Hg}^{2+}$, and $\mathrm{Zn}^{2+}$ have nearly equal cationic size, having the same charges, therefore requiring $5 \mathrm{~h}$ to attain equilibrium, while $\mathrm{Cd}^{2+}$ and $\mathrm{Pb}^{2+}$ have large atomic size, therefore requiring $6 \mathrm{~h}$ to attain equilibrium. The trend is in well agreement with earlier workers $[4,19,32,33]$.

(iii) Evaluation of the Distribution of Metal Ions at Different $p H$. The effect of $\mathrm{pH}$ on the metal binding capacity of the synthesized terpolymers shows that relative amount of metal ion adsorbed by the terpolymer resin increases with increasing $\mathrm{pH}$ of the medium (Table 6 ). The study was carried from $\mathrm{pH} 1.5$ to 6.5 to prevent absorption or hydrolysis or precipitation of the metal ions at higher $\mathrm{pH}$. The data on the distribution ratio as a function of $\mathrm{pH}$ indicates that the distribution of each metal between the polymers phase and aqueous phase increases with increasing $\mathrm{pH}$ of the medium. The magnitude of increase, however, is different for different metal cations.

The highest working $\mathrm{pH}$ is 3 in $\mathrm{Fe}^{3+}$ ions, because above this $\mathrm{pH} \mathrm{Fe}{ }^{3+}$ was found to be absorbed in the resin and it has lower distribution ratio since $\mathrm{Fe}^{3+}$ forms complex with ligand of electrolyte, which shows crowding effect. This steric hindrance maybe lowers the distribution ratio of $\mathrm{Fe}^{3+}$ ion. $\mathrm{Cu}^{2+}$ and $\mathrm{Ni}^{2+}$ have higher distribution ratio over $\mathrm{pH}$ range of 2.5 to 6.5 which may be due to the less steric hindrance. Thus the value of distribution ratio for given $\mathrm{pH}$ depends upon the nature and stability of chelates' formation for particular 
TABLE 5: Comparison of the rates of metal (M) ions ${ }^{a}$ uptake by 4-ASAUF terpolymer resin.

\begin{tabular}{|c|c|c|c|c|c|c|c|c|}
\hline \multirow{2}{*}{ Metal ion } & \multirow{2}{*}{$\mathrm{pH}$} & \multicolumn{7}{|c|}{ Percentage of metal ion uptake ${ }^{b}$ at different times $(\mathrm{h})$} \\
\hline & & 1 & 2 & 3 & 4 & 5 & 6 & 7 \\
\hline $\mathrm{Fe}^{3+}$ & 2.5 & 46 & 72 & 97 & - & - & - & - \\
\hline $\mathrm{Cu}^{2+}$ & 4.5 & 12 & 32 & 46.5 & 62.5 & 93 & - & - \\
\hline $\mathrm{Hg}^{2+}$ & 4.5 & 16 & 29 & 44 & 62 & 85 & - & - \\
\hline $\mathrm{Cd}^{2+}$ & 5 & 13 & 22.5 & 35.5 & 56 & 76 & 95 & - \\
\hline $\mathrm{Co}^{2+}$ & 5 & 14 & 32.5 & 47 & 71.5 & 87 & - & - \\
\hline $\mathrm{Zn}^{2+}$ & 5 & 4.5 & 27 & 42 & 62 & 71 & - & - \\
\hline $\mathrm{Ni}^{2+}$ & 5 & 5 & 19.5 & 42 & 71.5 & 88 & - & - \\
\hline $\mathrm{Pb}^{2+}$ & 6 & 6 & 18.5 & 38.5 & 72 & 77.5 & 89 & - \\
\hline
\end{tabular}

${ }^{\mathrm{a}}\left[\mathrm{M}\left(\mathrm{NO}_{3}\right)_{2}\right]=0.1 \mathrm{~mol} / \mathrm{L} ;$ volume $=2 \mathrm{~mL} ; \mathrm{NaNO}_{3}=1.0 \mathrm{~mol} / \mathrm{L} ;$ and volume $=25 \mathrm{~mL}$, room temperature

${ }^{\mathrm{b}}$ Metal ion uptake $=($ amount of metal ion absorbed $\times 100) /$ amount of metal ion absorbed at equilibrium.

TABLE 6: Distribution ratio $\mathrm{D}^{\mathrm{a}}$ of various metal ions ${ }^{\mathrm{b}}$ as function of the $\mathrm{pH}$ by 4-ASAUF terpolymer resin.

\begin{tabular}{lcccccccccc}
\hline \multirow{2}{*}{ Metal ion } & $\mathrm{pH}$ & \multicolumn{7}{c}{ Distribution ratio of metal ion at different $\mathrm{pH}$} \\
& & 1.5 & 2 & 2.5 & 3 & 3.5 & 4 & 5 & 6 & 6.5 \\
\hline $\mathrm{Fe}^{3+}$ & 2.5 & 62.35 & 98.50 & 188.55 & 398.0 & - & - & - & - \\
$\mathrm{Cu}^{2+}$ & 4.5 & - & - & 42.50 & 45.75 & 50.38 & 85.54 & 148.26 & 620.30 & 1026.32 \\
$\mathrm{Hg}^{2+}$ & 4.5 & - & - & 28.37 & 71.36 & 82.54 & 296.77 & 352.68 & 389.45 & 542.34 \\
$\mathrm{Cd}^{2+}$ & 5 & - & - & 142.24 & 155.42 & 211.21 & 266.42 & 333.84 & 441.45 & 616.42 \\
$\mathrm{Co}^{2+}$ & 5 & - & - & 22.22 & 31.32 & 54.33 & 69.79 & 116.45 & 242.23 & 322.88 \\
$\mathrm{Zn}^{2+}$ & 5 & - & - & 22.30 & 38.82 & 47.80 & 73.74 & 122.70 & 236.63 & 292.75 \\
$\mathrm{Ni}^{2+}$ & 5 & - & - & 0.68 & 17.83 & 52.33 & 109.42 & 266.42 & 548.36 & 1025.3 \\
$\mathrm{~Pb}^{2+}$ & 6 & - & - & 13.65 & 21.40 & 27.16 & 36.26 & 55.16 & 124.70 & 232.42 \\
\hline
\end{tabular}

${ }^{\mathrm{a}} \mathrm{D}=$ weight (in $\mathrm{mg}$ ) of metal ions taken up by $1 \mathrm{~g}$ of terpolymer/weight (in $\mathrm{mg}$ ) of metal ions present in $1 \mathrm{~mL}$ of solution.

${ }^{\mathrm{b}}\left[\mathrm{M}\left(\mathrm{NO}_{3}\right)_{2}\right]=0.1 \mathrm{~mol} / \mathrm{L}$; volume $=2 \mathrm{ml} ; \mathrm{NaNO}_{3}=1.0 \mathrm{~mol} / \mathrm{L}$; and volume $=25 \mathrm{~mL}$, time $24 \mathrm{~h}$ (equilibrium state) at room temperature.

metal ion $[4,19,33]$. In the case of $\mathrm{Cd}^{2+}$ and $\mathrm{Pb}^{2+}$, purely electrostatic factors are responsible. The ion uptake capacity of $\mathrm{Cd}^{2+}$ is lower owing to the large size of its hydrated ion than that of $\mathrm{Cu}^{2+}$. The steric influence of the amine group and hydroxyl group in 4-ASAUF resin is probably responsible for their observed low binding capacities for various metal ions. The higher value of distribution ratio for $\mathrm{Cu}^{2+}$ and $\mathrm{Ni}^{2+}$ at $\mathrm{pH}$ 2.5 to 6.5 may be due to the formation of most stable complex with chelating ligands. Therefore the copolymer under study has more selectivity of $\mathrm{Cu}^{2+}$ and $\mathrm{Ni}^{2+}$ ions in the range of $\mathrm{pH}$ 2.5 to 6.5 than other ions which form rather weak complex, while from $\mathrm{pH} 1.5$ to 3 the polymer has more selectivity of $\mathrm{Fe}^{3+}$ ions. The order of distribution ratio of metal ions measured in $\mathrm{pH}$ range 1.5 to 6.5 is found to be $\mathrm{Fe}^{3+}>\mathrm{Cu}^{2+}>$ $\mathrm{Ni}^{2+}>\mathrm{Hg}^{2+}>\mathrm{Zn}^{2+}>\mathrm{Co}^{2+}>\mathrm{Pb}^{2+}>\mathrm{Cd}^{2+}[4,19,33]$.

The 4-ASAUF terpolymer resin is a cation-exchange resin and in cation-exchange resin the equilibrium may be expressed in terms of mass action law and the relative amount of metal ions in the resin phase is determined by the relative concentrations of these ions in the bulk of the solution:

$$
\begin{aligned}
& \left(\text { resin } \mathrm{OH}^{-}\right) \mathrm{H}^{+}+\mathrm{M}^{+}(\text {in solution }) \rightarrow\left(\text { resin } \mathrm{OH}^{-}\right) \\
& \mathrm{M}^{+}+\mathrm{H}^{+}(\text {in solution }) \\
& K=\left[\mathrm{H}^{+}\right]\left[\left(\text {resin } \mathrm{OH}^{-}\right) \mathrm{M}^{+}\right] /\left[\left(\text {resin } \mathrm{OH}^{-}\right) \mathrm{H}^{+}\right]\left[\mathrm{H}^{+}\right] \text {. }
\end{aligned}
$$

Equilibrium constant $(K)$ of this type is useful for comparing the relative affinities for a resin towards various ions. The cations are arranged in an affinity scale according to the numerical value of $K$. For the metal ions under investigation, the relative affinity is $\mathrm{Fe}^{3+}>\mathrm{Cu}^{2+} \approx \mathrm{Ni}^{2+}>\mathrm{Cd}^{2+} \approx \mathrm{Hg}^{2+}>$ $\mathrm{Co}^{2+} \approx \mathrm{Zn}^{2+} \approx \mathrm{Pb}^{2+}$.

The strength of electrolyte and dielectric constant also affects the metal distribution or accumulation of resin.

\section{Conclusion}

The metal complexes taken in the present study are $\mathrm{pH}$ dependent and each has a definite $\mathrm{pH}$ for optimum chelation, a useful property to employ a particular metal to be separated from a solution, using this terpolymer. The surface of the terpolymer resin was found to be more amorphous than crystalline in nature, clearly indicated by void volume fraction and sodium exchange capacity of the synthesized resin for ion-exchange applications. Synthesis of targeted terpolymer (4-ASAUF) has been achieved and the structure is confirmed by various spectral studies which are supported by the results obtained from elemental analysis. 


\section{Conflict of Interests}

The authors declare that there is no conflict of interests regarding the publication of this paper.

\section{Acknowledgments}

The authors wish to express their sincere thanks to Dr. G. M. Deshmukh, Director In-Charge, Laxminarayan Institute of Technology, R.T.M. Nagpur University, Nagpur, for the constant encouragement and support. They would also like to thank SAIF, Punjab University, Chandigarh, for carrying out spectral analysis, and University Grant Commission (UGC) for their financial support.

\section{References}

[1] D. Prabhakaran and M. S. Subramanian, "A new chelating sorbent for metal ion extraction under high saline conditions," Talanta, vol. 59, no. 6, pp. 1227-1236, 2003.

[2] S. Nabi, A. Alim, A. Islam, and M. Amjad, "Column chromatographic separation of metal ions on 1-(2-pyridylazo)-2-napthol modified Amberlite IR-120 resin," Journal of Separation Science, vol. 28, no. 18, pp. 2463-2467, 2005.

[3] M. M. Jadhao, L. J. Paliwal, and N. S. Bhave, "Ion-exchange properties of $2,2^{\prime}$-dihydroxybiphenyl-urea-formaldehyde terpolymer resins," Desalination, vol. 247, no. 1-3, pp. 456-465, 2009.

[4] M. Karunakaran and C. Magesh, "Thermal and ion-exchange studies on chelating terpolymer resins derived from o cresol urea formaldehyde," Arabian Journal of Chemistry, vol. 4, no. 3, pp. 339-348, 2011.

[5] C. Magesh, C. T. Vijayakumar, and M. Karunakaran, "Anthranilic acid-urea-formaldehyde terpolymer resin and their ionexchange properties," International Journal of Chemistry and Applications, vol. 2, no. 1, pp. 21-32, 2010.

[6] R. N. Singru, W. B. Gurnule, V. A. Khati, A. B. Zade, and J. R. Dontulwar, "Eco-friendly application of p-cresol-melamineformaldehyde polymer resin as an ion-exchanger and its electrical and thermal study," Desalination, vol. 263, no. 1-3, pp. 200210, 2010 .

[7] M. E. Mahmoud, I. M. M. Kenawy, M. A. H. Hafez, and R. R. Lashein, "Removal, preconcentration and determination of trace heavy metal ions in water samples by AAS via chemically modified silica gel N-(1-carboxy-6-hydroxy) benzylidenepropylamine ion exchanger," Desalination, vol. 250, no. 1, pp. 62-70, 2010.

[8] M. J. Orell, G. D. Pizarro, O. G. Marambio, and K. E. Geckeler, "Novel hydrogels based on itaconic acid and citraconic acid: synthesis, metal ion binding, and swelling behavior," Journal of Applied Polymer Science, vol. 113, no. 1, pp. 104-111, 2009.

[9] S. S. Rahangdale, A. B. Zade, and W. B. Gurnule, "Chelation ion exchange properties of 2, 4-dihydroxyacetophenone-biuret -formaldehyde terpolymer resin," E-Journal of Chemistry, vol. 6, no. 3, pp. 835-843, 2009.

[10] M. V. Tarase, W. B. Gurnule, and A. B. Zade, "Ion exchange properties of a terpolymer resin derived from 2, 4-dihydroxybenzaldehyde, oxamide and formaldehyde," E-Journal of Chemistry, vol. 6, no. 3, pp. 639-650, 2009.
[11] R. N. Singru and W. B. Gurnule, "Chelation ion-exchange study of copolymer resin derived from 8-hydroxyquinoline 5sulphonic acid, oxamide, and formaldehyde," Journal of Applied Polymer Science, vol. 116, no. 6, pp. 3356-3366, 2010.

[12] W. B. Gurnule and D. B. Patle, "Metal ion binding properties of a copolymer resin: synthesis, characterization, and its applications," Polymer Bulletin, vol. 66, no. 6, pp. 803-820, 2011.

[13] W. B. Gurnule, H. D. Juneja, and L. J. Paliwal, "Ion-exchange properties of a salicylic acid-melamine-formaldehyde terpolymer resin," Reactive and Functional Polymers, vol. 50, no. 2, pp. 95-100, 2002.

[14] S. S. Butoliya, A. B. Zade, and W. B. Gurnule, "Terpolymer resin viii: chelation ion-exchange properties of 2,4-dihydroxybenzophenone-oxamide-formaldehyde terpolymer resins," Journal of Applied Polymer Science, vol. 113, no. 1, pp. 1-9, 2009.

[15] M. A. R. Ahamed, R. S. Azarudeen, M. Karunakaran, and A. R. Burkanudeen, "Synthesis, characterization, metal ion binding capacities and applications of a terpolymer resin of anthranilic acid/salicylic acid/formaldehyde," Iranian Polymer Journal, vol. 19, no. 8, pp. 635-646, 2010.

[16] R. S. Azarudeen, M. A. R. Ahamed, and A. R. Burkanudeen, "Chelating terpolymer resin: synthesis, characterization and its ion-exchange properties," Desalination, vol. 268, no. 1-3, pp. 90 96, 2011.

[17] R. Manavalan and M. M. Patel, "Chelation ion-exchange prop-erties of salicylic acid/thiourea/trioxane terpolymers," Die Makromolekulare Chemie, vol. 184, no. 4, pp. 717-723, 2003.

[18] A. Vogel, Text Book of Quantitative Chemical Analysis, Longman, London, UK, 5th edition, 1989.

[19] R. S. Azarudeen and A. R. Burkanudeen, "Sorption investigation on the removal of metal ions from aqueous solutions using chelating terpolymer resin," Research on Chemical Intermediates, vol. Volume 38, no. 9, pp. 1255-2173, 2012.

[20] W. B. Gurnule, P. K. Rahangdale, L. J. Paliwal, and R. B. Kharat, "Synthesis, characterization and ion-exchange properties of 4-hydroxyacetophenone, biuret and formaldehyde terpolymer resins," Reactive and Functional Polymers, vol. 55, no. 3, pp. 255265, 2003.

[21] K. Nakanishi, Infrared Absorption Spectroscopy Practical, Golden Day, INC and Nankodo, Tokyo, Japan, 1967.

[22] A. I. Vogel, Text Book of Practical Organic Chemistry, Longman Scientific and Technical, London, UK, 1989.

[23] A. R. Burkanudeen, R. S. Azarudeen, M. A. R. Ahamed, and W. B. Gurnule, "Kinetics of thermal decomposition and antimicrobial screening of terpolymer resins," Polymer Bulletin, vol. 67, no. 8, pp. 1553-1568, 2011.

[24] R. M. Silverstein and G. C. Bassler, Spectrometric Identification of Organic Compounds, Wiley, New York, NY, USA, 2nd edition, 1967.

[25] W. Kemp, Organic Spectroscopy, Macmillan Press, Hong Kong, 1975.

[26] R. M. Silverstein, G. C. Bassler, and T. C. Morrill, Spectrometric Identification of Organic Compounds, Wiley, Singapore, 5th edition, 1991.

[27] R. K. Samal, B. K. Senapati, and T. B. Behuray, "Synthesis and characterization of aniline-doped mixed copolymer resins. II," Journal of Applied Polymer Science, vol. 62, no. 4, pp. 655-660, 1996.

[28] W. B. Gurnule, P. K. Rahangadale, R. B. Kharat, and L. J. Paliwal, "Synthesis and characterization of copolymer derived from 2hydroxyacetophenone, oxamide and formaldehyde," Progress in 
Crystal Growth and Characterization of Materials, vol. 45, no. 1-2, pp. 155-160, 2002.

[29] E. Pretsch, P. Buhlmann, and C. Afflolter, Structure Determination of Organic Compounds, Springer, New York, NY, USA, 2000.

[30] R. C. DeGeiso, L. G. Donaruma, and E. A. Tomic, "Chelation ion exchange properties of a salicylic acid-formaldehyde polymer," Analytical Chemistry, vol. 34, no. 7, pp. 845-847, 1962.

[31] H. P. Gregor, M. Tasfer, L. Cilardl, and E. I. Becker, "Chelate ion exchange resins," Industrial and Engineering Chemistry, vol. 44, no. 12, pp. 2834-2839, 1952.

[32] P. E. P. Michael, J. M. Barbe, H. D. Juneja, and L. J. Paliwal, "Synthesis, characterization and thermal degradation of 8hydroxyquinoline-guanidine-formaldehyde terpolymer," European Polymer Journal, vol. 43, no. 12, pp. 4995-5000, 2007.

[33] S. S. Rahangdale, A. B. Zade, and W. B. Gurnule, “Terpolymer resin II: synthesis, characterization, and ion-exchange properties of 2,4-dihydroxyacetophenone-dithiooxamideformaldehyde terpolymers," Journal of Applied Polymer Science, vol. 108, no. 2, pp. 747-756, 2008. 

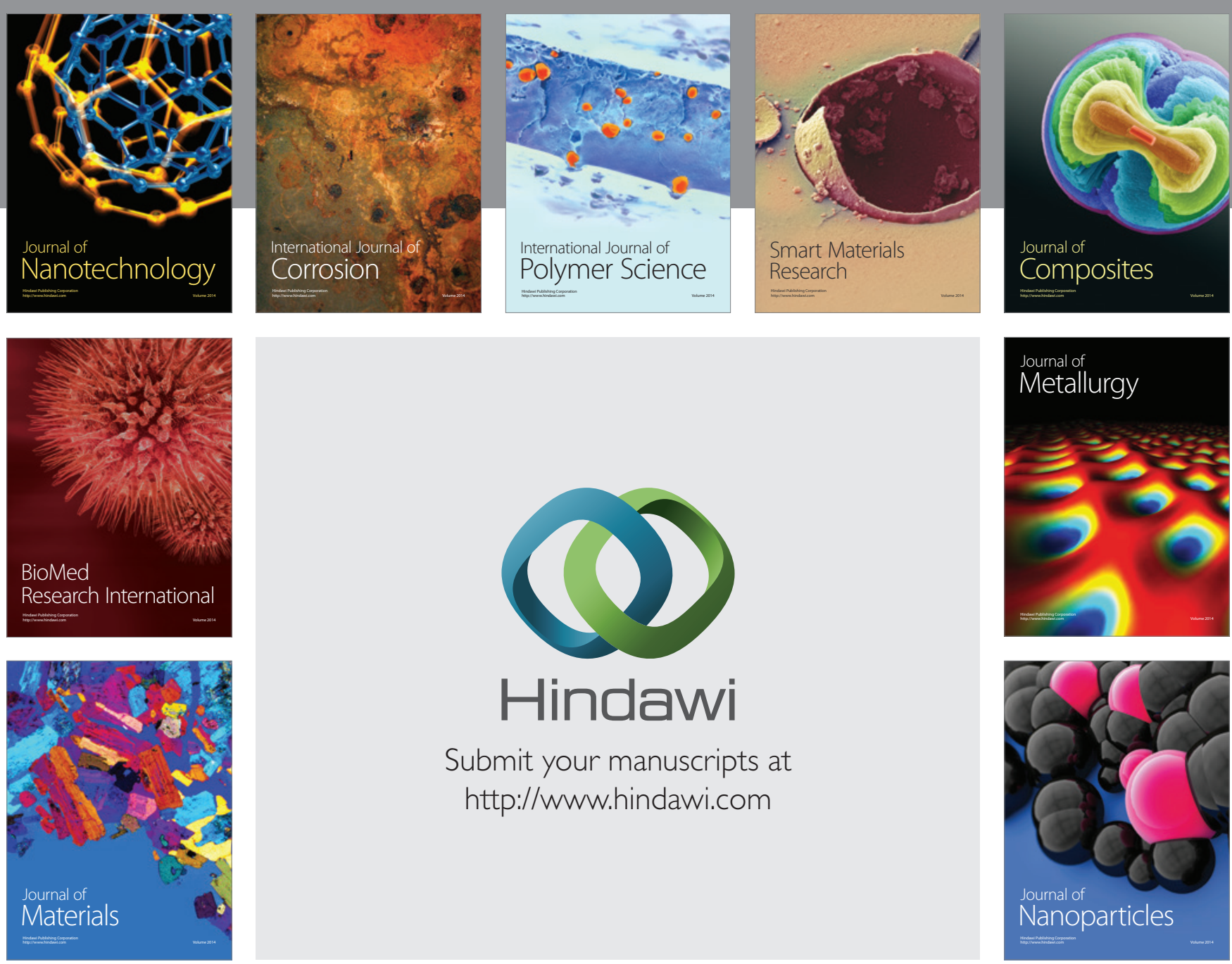

Submit your manuscripts at http://www.hindawi.com
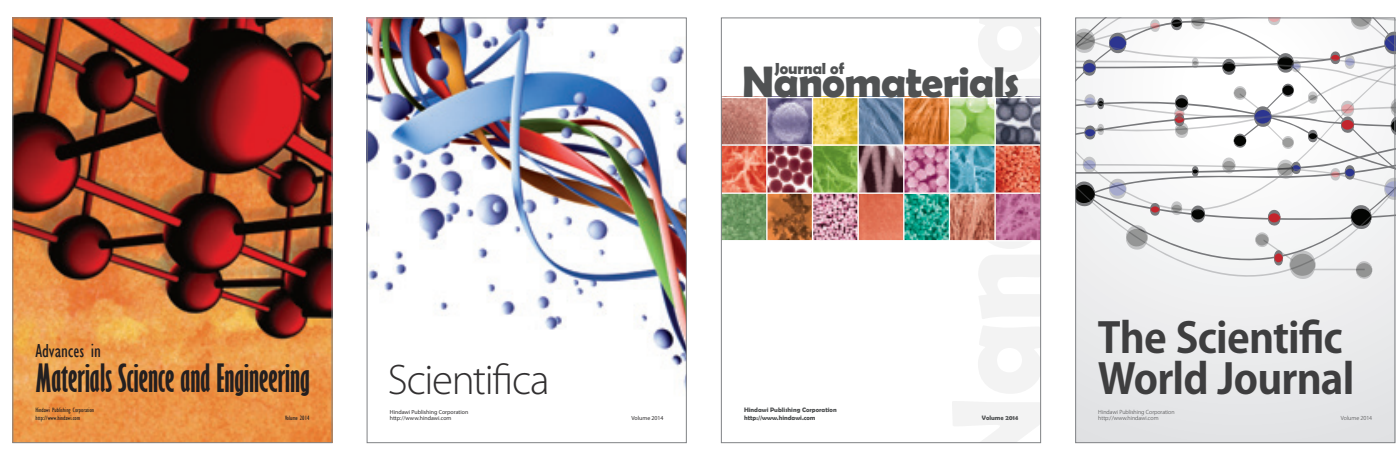

\section{The Scientific World Journal}
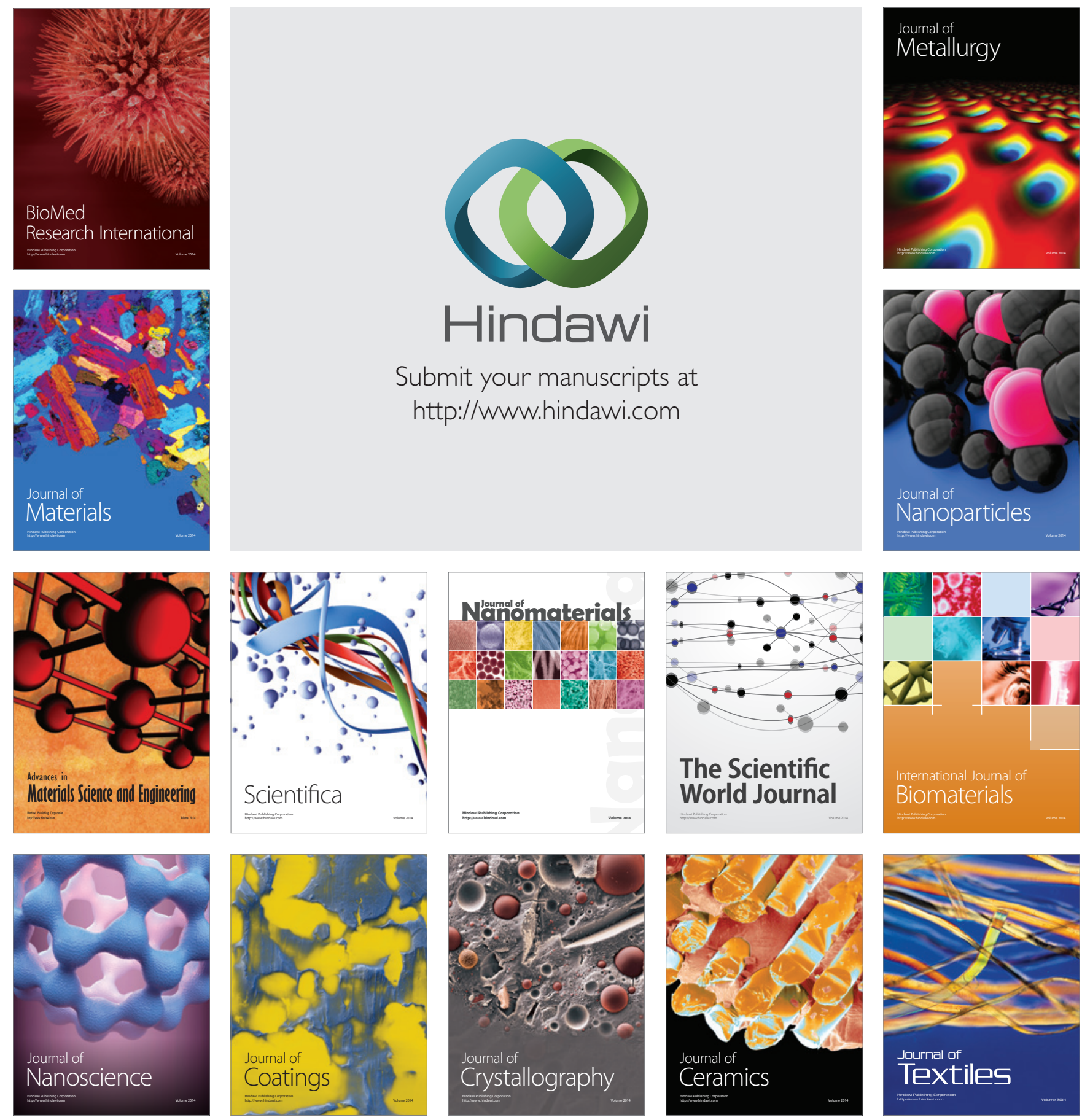